\title{
Clinical predictors of pathological complete response to neoadjuvant chemotherapy in triple-negative breast cancer
}

\author{
AYAKO NAKASHOJI $^{1}$, AKIRA MATSUI $^{1}$, AIKO NAGAYAMA ${ }^{1}$, YUKO IWATA $^{1}$, \\ MANAMI SASAHARA $^{1}$ and YUYA MURATA ${ }^{2}$ \\ Departments of ${ }^{1}$ Breast Surgery and ${ }^{2}$ Clinical Examination, National Hospital Organization Tokyo Medical Center, \\ Tokyo 152-8902, Japan
}

Received September 18, 2016; Accepted April 28, 2017

DOI: $10.3892 / 01.2017 .6692$

\begin{abstract}
The response of triple-negative breast cancer (TNBC) to chemotherapy is heterogeneous; particular subtype classifications based on mRNA gene expression analysis have been demonstrated to be associated with a pathological complete response (pCR). The aim of the present study was to investigate additional clinical and pathological characteristics associated with pCR status. The pathological and clinical characteristics of 40 TNBC patients who underwent neoadjuvant chemotherapy followed by surgery were retrospectively analyzed by dividing the cases into two groups according to the response to treatment: pCR $(n=12)$ and non-pCR $(n=28)$. Clinically, patients in the pCR group presented tumors with a significantly less advanced Tumor-Node-Metastasis stage $(\mathrm{P}=0.030)$ and mammographic calcification was less common (17 vs. $58 \%$; $\mathrm{P}=0.034)$. Pathologically, whereas all cases in the pCR group $(12 / 12,100 \%)$ were of the histological type 'invasive ductal carcinoma, not otherwise specified' (IDC-NOS), the non-pCR group consisted of a lower proportion of IDC-NOS cases $(20 / 28,71 \%)$ and more cases of special histological types, including mucinous, metaplastic, medullary and apocrine carcinomas $(\mathrm{P}=0.079)$. The positive rates of androgen receptor (AR) and forkhead-box A1 (FOXA1) tended to be lower in the pCR group (AR, 0 vs. $29 \%, \mathrm{P}=0.079$; FOXA1, 8 vs. $29 \%$, $\mathrm{P}=0.233)$. The Ki-67 score was significantly higher in the $\mathrm{pCR}$ group than in the non-pCR group $(\mathrm{P}=0.041)$. The results suggest that patients with TNBC who present with clinically less advanced tumors and less frequent mammographic calcification are more likely to respond to chemotherapy. From a pathological standpoint, IDC-NOS type, negative AR status
\end{abstract}

Correspondence to: Dr Akira Matsui, Department of Breast Surgery, National Hospital Organization Tokyo Medical Center, 2-5-1 Higashigaoka, Meguro, Tokyo 152-8902, Japan

E-mail: matsuiakira@kankakuki.go.jp

Key words: triple-negative breast cancer, neoadjuvant chemotherapy, pathological complete response, mammographic calcifications, androgen receptor and higher Ki-67 scores may be associated with chemotherapy sensitivity.

\section{Introduction}

Triple-negative breast cancer (TNBC) is characterized by the absence of estrogen receptor (ER) or progesterone receptor (PgR) expression, and the lack of human epidermal growth factor receptor 2 (HER2) gene amplification. TNBC represents $15-20 \%$ of all breast cancer cases; it exhibits a distinctly aggressive nature, with higher rates of relapse and shorter overall survival times compared with the other breast cancer subtypes $(1,2)$.

TNBC is characterized by a heterogeneous immunohistochemical phenotype. The majority of TNBCs have a high-grade 'invasive ductal carcinoma, not otherwise specified' (IDC-NOS) histology. However, a significant proportion of other relatively rare histotypes (medullary, metaplastic, adenoid cystic and apocrine carcinomas) may also lack expression of ER, PgR and HER2 (3). From a genetic standpoint, TNBCs include different molecular subtypes. Lehmann et al (4) identified six different TNBC subtypes that express unique gene expression patterns by analyzing the mRNA gene expression profiles from 21 breast cancer datasets, including basal-like (BL)1 and 2, immune-modulatory (IM), mesenchymal (M), mesenchymal stem-like (MSL), luminal androgen receptor (LAR) and unstable (UNS) subtypes. Recently, these six subtypes (TNBC type: BL1, BL2, IM, M, MSL and LAR) were refined to four (TNBC type-4: BL1, BL2, M and LAR), when considering that the IM and MSL subtypes represent tumors with substantial infiltrating lymphocytes and tumor-associated mesenchymal cells (5).

Cytotoxic chemotherapy is currently the only treatment option for TNBC; it has been demonstrated that TNBC is more chemotherapy-sensitive than ER-positive tumors (6,7). A pathological complete response (pCR) to neoadjuvant chemotherapy (NAC) of TNBC is highly associated with prolonged overall and event-free survival times. In previous studies, $20-30 \%$ of patients with TNBC achieved pCR in the neoadjuvant setting and the response of TNBC to chemotherapy was heterogeneous (6,8-10). Masuda et al (11) reported that Lehmann's six gene expression subtypes (TNBCtype) were associated with pCR status, with the BL1 subtype presenting 
a high rate of pCR (52\%) compared with the M, IM, MSL and LAR subtypes, which presented relatively low pCR rates (31, 30,23 and $10 \%$, respectively).

However, subtype classification by mRNA expression analysis is not yet common, convenient or economic enough to put into daily clinical use. Thus, the present study aimed to investigate additional clinical and pathological characteristics that are associated with $\mathrm{pCR}$ status as a means to predict the response to chemotherapy using information that is already readily available in daily clinical practice. If the effects could be predicted prior to actually performing chemotherapy on patients with TNBC, eventually unnecessary severe side effects caused by ineffective chemotherapy could be avoided.

\section{Patients and methods}

Patients. Of the 1,773 patients with operable primary breast cancer on record between January 2007 and January 2016 in the National Hospital Organization Tokyo Medical Center (Tokyo, Japan), a total of 40 were diagnosed with TNBC by needle biopsy, classified clinically as Stage II (12) or higher and required NAC. All patients were female, and no patient was excluded from the present analysis. The characteristics of the 40 patients are described in Table I. The effectiveness of chemotherapy following surgery was pathologically evaluated. The patients were divided into two groups according to their response: pCR $(n=12)$ and non-pCR $(n=28)$. The clinical and pathological data of the patients were retrieved from medical records and retrospectively reviewed and analyzed according to these groupings. Ethical approval for the present study was provided by the Ethics Committee at the National Hospital Organization Tokyo Medical Center, and the study was performed in accordance with the appropriate ethical standards.

Examinations prior to NAC. Prior to NAC, imaging studies, blood tests and physical measurements were performed. Digital mammography was performed for 38 patients; mammography was not possible for 2 patients in the non-pCR group due to skin ulceration or bleeding of the tumor. Mammograms were performed in the mediolateral oblique and craniocaudal views for each patient; additional views were performed when the lesion was not clearly identified by these 2 views. The mammograms were evaluated according to the criteria established by the Japan Central Organization on Quality Assurance of Breast Cancer Screening (13), by $\geq 2$ radiologists or surgeons certified by the aforementioned organization. The mammographic findings were described as masses, calcifications (typically benign calcifications were excluded) or other (including focal asymmetric densities and architectural distortions).

The clinical Tumor-Node-Metastasis (TNM) classification (14) and stage (12) were evaluated and determined prior to the administration of NAC. The tumor size and nodal status were evaluated by ultrasonography, magnetic resonance imaging or computed tomography. Distant metastasis was detected with computed tomography.

The height and body weight of the patients were recorded, and body mass index (BMI) was calculated, with BMI $\geq 25 \mathrm{~kg} / \mathrm{m}^{2}$ defined as obese. The blood tests performed included regular measurement of total cholesterol level and 3 breast cancer tumor markers (carbohydrate antigen
15-3, carcinoembryonic antigen and National Cancer Center-Stomach-439) as described previously (15-17).

Treatment. The patients were treated with chemotherapy regimens, including anthracyclines (5-fluorouracil, $500 \mathrm{mg} / \mathrm{m}^{2}$; epirubicin, $100 \mathrm{mg} / \mathrm{m}^{2}$; or cyclophosphamide, $500 \mathrm{mg} / \mathrm{m}^{2}$; triweekly for 4 cycles) and/or taxanes (docetaxel, $70 \mathrm{mg} / \mathrm{m}^{2}$; triweekly for 4 cycles; or nab-paclitaxel, $100 \mathrm{mg} / \mathrm{m}^{2}$; weekly for 12 cycles). Subsequent to NAC, the patients underwent mastectomy or partial mastectomy with axillary lymph node dissection or sentinel lymph node biopsy.

Histological assessment of tissue specimens. All microscopy slides were independently evaluated by $\geq 2$ senior pathologists. Cases of breast cancer with negative ER, PgR and HER2 were diagnosed as TNBC by core needle biopsy prior to all treatment.

The expression of ER, PgR, Ki-67, androgen receptor (AR) and forkhead-box A1 (FOXA1) were evaluated using semiquantitative immunohistochemistry (IHC) scoring of the percentage of cells with positive nuclear staining (1-100\%) (Fig. 1). The following antibodies were used for IHC: ER mouse monoclonal antibody (clone, 1D5SP1; pre-diluted kit; cat. no. 790-4323; Ventana Medical Systems, Inc., Innovation Park Drive, Tucson, AZ, USA), PgR mouse monoclonal antibody (clone, 1E2; pre-diluted kit; cat. no. 790-2223; Ventana Medical Systems, Inc.) AR mouse monoclonal antibody (clone, AR441; dilution, 1:50; cat. no. M3562; Dako; Agilent Technologies, Inc., Santa Clara, CA, USA), HER2 mouse monoclonal antibody (clone, 4B5; pre-diluted kit; cat. no. 790-2991; Ventana Medical Systems, Inc.), FOXA1 goat polyclonal antibody (clone, ab5089; dilution, 1:50; cat. no. GR120766-17; Abcam, Cambridge, UK) and Ki-67 mouse monoclonal antibody (MIB-1; dilution, 1:100; cat. no. M7240; Dako; Agilent Technologies, Inc.). Positivity for ER, PgR, AR or FOXA1 was defined as nuclear staining in $\geq 1 \%$ of tumor cells. Ki-67 expression was considered low when $\leq 50 \%$ and high when $>50 \%$ stained cells were observed.

HER2 status was assessed using IHC and/or fluorescence in situ hybridization. HER2 expression was scored as 0 to $3+$ by IHC based on ASCO/CAP recommendations (18), and HER 2 positivity was defined by an IHC score of $3+$ or by the identification of HER2 gene amplification from fluorescence in situ hybridization.

Surgical specimens were used to evaluate the pathological response of NAC. pCR was defined as the absence of any residual invasive cancer observed following hematoxylin and eosin (H\&E) staining of the resected breast specimen. Residual ductal carcinoma in situ was included in the pCR category.

The specimens were fixed in $10 \%$ neutral buffered formalin immediately following resection for $24-48 \mathrm{~h}$ at $20^{\circ} \mathrm{C}$. Subsequent to the specimens being cut in $5 \mathrm{~mm}$ slices, an automatic $\mathrm{H} \& \mathrm{E}$ stain was applied for $40 \mathrm{~min}$ at $25^{\circ} \mathrm{C}$. The H\&E specimens were examined at magnifications, $\mathrm{x} 40-100$ views, and also at magnifications x200-400 when pathologists required more detailed information of each cell to make a diagnosis. Immunostaining specimens were studied at magnifications, $\mathrm{x} 100$ or $\mathrm{x} 200$.

Statistical analysis. For comparison of the sample means, an independent sample t-test was performed. Associations between 
Table I. Clinical features of patients with TNBC according to pCR status $(n=40)$.

\begin{tabular}{|c|c|c|c|}
\hline Characteristic & $\mathrm{pCR}$ & non-pCR & P-value \\
\hline Total, $\mathrm{n}$ & 12 & 28 & \\
\hline Age, years & & & 0.974 \\
\hline Mean & 53 & 53 & \\
\hline Range & $27-82$ & $32-74$ & \\
\hline Menopausal status, n (\%) & & & 0.471 \\
\hline Premenopausal & $6(50)$ & $12(43)$ & \\
\hline Postmenopausal & $6(50)$ & $16(57)$ & \\
\hline Obesity rate $^{\mathrm{a}}, \mathrm{n}(\%)$ & & & 0.570 \\
\hline Obese & $3(25)$ & $8(29)$ & \\
\hline Non-obese & $9(75)$ & $20(71)$ & \\
\hline Blood serum T-cholesterol, mg/dl & & & 0.200 \\
\hline Mean & 195 & 208 & \\
\hline Range & $168-249$ & $122-277$ & \\
\hline cT prior to NAC, n (\%) & & & 0.009 \\
\hline cT1 & $1(8)$ & $0(0)$ & \\
\hline cT2 & $10(83)$ & $13(46)$ & \\
\hline cT3 & $1(8)$ & $4(14)$ & \\
\hline cT4 & $0(0)$ & $11(39)$ & \\
\hline $\mathrm{cN}$ prior to $\mathrm{NAC}, \mathrm{n}(\%)$ & & & 0.436 \\
\hline $\mathrm{cNO}$ & $7(58)$ & $11(39)$ & \\
\hline $\mathrm{cN} 1$ & $4(33)$ & $14(50)$ & \\
\hline $\mathrm{cN} 2$ & $1(8)$ & $1(4)$ & \\
\hline cStage prior to NAC, n (\%) & & & 0.030 \\
\hline cStage II & $11(92)$ & $13(46)$ & \\
\hline cStage III & $1(8)$ & $12(43)$ & \\
\hline cStage IV & $0(0)$ & $3(11)$ & \\
\hline NAC regimen, n (\%) & & & 1.000 \\
\hline Ant only & $0(0)$ & $1(4)$ & \\
\hline Tax only & $0(0)$ & $2(7)$ & \\
\hline Ant/Tax & $12(100)$ & $25(89)$ & \\
\hline
\end{tabular}

${ }^{a}$ Defined as a body mass index $\geq 25 \mathrm{~kg} / \mathrm{m}^{2}$. TNBC, triple-negative breast cancer; $\mathrm{pCR}$, pathological complete response; cT, tumor size classification; NAC, neoadjuvant chemotherapy; cN, node classification; cStage, clinical stage; Ant, anthracyclines; Tax, taxanes.

pCR and clinicopathological characteristics were assessed with a $\chi^{2}$ test, Fisher's exact test or Mann-Whitney U-test, as appropriate. Clinical features of patients with TNBC according to pCR status were assessed by $\chi^{2}$ test or Fisher's exact test. Mammographic features in patients with triple negative breast cancer according to pCR status were assessed by Fisher's exact test, and AR positive rate was additionally assessed by Man-Whitney U test. All analyses were performed using SPSS statistical software (version 23.0; IBM Corp., Armonk, NY, United States). P<0.05 was considered to indicate a statistically significant difference.

\section{Results}

Clinical findings. There were significant differences in the likelihood of pCR according to TNM classification and clinical stage; patients in the pCR group presented with a less advanced $\mathrm{T}$ classification $(\mathrm{P}=0.009)$ and clinical stage $(\mathrm{P}=0.030)$ compared with non-pCR patients (Table I). The pCR group tended to have lower serum total cholesterol levels compared with the non-pCR group, although the difference was not statistically significant $(195 \pm 40$ vs. $208 \pm 20 \mathrm{mg} / \mathrm{dl}$; $\mathrm{P}=0.200$ ). There were no significant differences between the pCR and non-pCR groups with regard to mean age, menopausal status, obesity, NAC regimen or tumor marker status.

Mammography findings. There was no difference between the pCR and non-pCR groups in the rate of the mammographic presentation of masses (67 vs. 77\%; P=0.694). However, there was a significant difference in the presentation of mammographic calcification; pCR patients were less likely to exhibit calcification in mammograms compared with non-pCR patients (17 vs. $58 \%$; $\mathrm{P}=0.034$; Table II). 
Table II. Mammographic features in patients with triple negative breast cancer according to pCR status $(n=38)$.

\begin{tabular}{lrrr}
\hline Characteristic & pCR & non-pCR & P-value \\
\hline Total, n & 12 & 26 & \\
$\begin{array}{l}\text { Presence of mass, n (\%) } \\
\quad \text { Yes }\end{array}$ & $8(67)$ & $20(77)$ & 0.694 \\
$\quad$ No & $4(33)$ & $6(23)$ & \\
Presence of calcifications, n (\%) & & & 0.034 \\
$\quad$ Yes & $2(17)$ & $15(58)$ & \\
No & $10(83)$ & $11(42)$ & \\
\hline
\end{tabular}

pCR, pathological complete response.

Pathological findings. The histological types of the two groups tended to differ, although the difference was not significant $(\mathrm{P}=0.079)$; All cases in the pCR group $(12 / 12,100 \%)$ were IDC-NOS, whereas the non-pCR group included less cases of IDC-NOS $(20 / 28,71 \%)$ and more special histological types, including mucinous, metaplastic, medullary and apocrine carcinomas.

The positive rates for AR and FOXA1 were lower in the pCR group, although no significant difference was observed (AR positive rate, 0 vs. 29\%, $\mathrm{P}=0.079$; FOXA1 positive rate, 8 vs. $29 \%$; $P=0.233$ ), as assessed with a Fisher's exact test; AR positivity was significantly less common in the $\mathrm{pCR}$ group when considered with a Mann-Whitney $\mathrm{U}$ test $(\mathrm{P}=0.043$; Fig. 2). Ki-67 scores were significantly higher in the pCR group than in the non-pCR group, as assessed with a Fisher's test $(\mathrm{P}=0.041$; Table III).

\section{Discussion}

The results of the present study suggested that chemotherapy-sensitive patients with TNBC present clinically less advanced tumors with less frequent mammographic calcifications, negative AR status and higher Ki-67 scores.

Nwaogu et al (7) demonstrated that lower clinical stage and negative lymph node involvement were associated with pCR in all breast cancer subtypes. In accordance with these findings, in the pCR group of patients with TNBC in the present study, the primary tumor status, lymph node status and clinical stage were less advanced. It is simple and reasonable to hypothesize that the tumor burden influences the treatment efficiency. It may be of note that the T4 category, indicating invasion of the skin or chest wall, was particularly frequent in non-pCR patients in the present study. Thus, not only the size or volume of the tumor, but also its robust invasive characteristics may influence the treatment effectiveness. Additionally, Lehmann et al (5) reported that BL1 tumors, which are more responsive to chemotherapy, presented at a lower clinical stage than BL2 and LAR tumors.

Mammographic calcifications reflect the intraductal component of tumor cells (19). Considering the results of the present study, this may suggest that tumors with a rich
Table III. Pathological features in TNBC patients according to pCR status $(n=40)$.

\begin{tabular}{|c|c|c|c|}
\hline Characteristic & $\mathrm{pCR}$ & non-pCR & P-value \\
\hline Total, $\mathrm{n}$ & 12 & 28 & \\
\hline Histological type, n (\%) & & & 0.079 \\
\hline IDC-NOS & $12(100)$ & $20(71)$ & \\
\hline Specific type & $0(0)$ & $8(29)$ & \\
\hline Ki-67 score ${ }^{\mathrm{a}}, \mathrm{n}(\%)$ & & & 0.041 \\
\hline Low & $2(17)$ & $15(54)$ & \\
\hline High & $10(83)$ & $13(46)$ & \\
\hline Androgen receptor status, $\mathrm{n}(\%)$ & & & 0.079 \\
\hline Positive & $0(0)$ & $8(29)$ & \\
\hline Negative & $12(100)$ & $20(71)$ & \\
\hline Forkhead-box A1 status, n (\%) & & & 0.233 \\
\hline Positive & $1(8)$ & $8(29)$ & \\
\hline Negative & $11(92)$ & $20(71)$ & \\
\hline
\end{tabular}

${ }^{a} \mathrm{Ki}-67$ score was defined as high when staining was $>50 \%$. TNBC, triple-negative breast cancer; $\mathrm{pCR}$, pathological complete response; IDC-NOS, invasive ductal carcinoma, not otherwise specified.

intraductal component may be less sensitive to chemotherapy. Furthermore, Li et al (20) reported that ER-, PgR- or HER2-positive tumors, which are less sensitive to chemotherapy than TNBCs, present with more mammographic calcifications than TNBCs.

Bae et al (21) further reported that mammographic calcifications are significantly associated with AR-positive TNBC, compared with AR-negative TNBC, and that AR-positive TNBC was more likely to have a ductal carcinoma in situ component. As previously mentioned, the LAR subgroup exhibited poor sensitivity to chemotherapy in the study by Masuda et al (11). Furthermore, Asano et al (22) recently reported that the rate of $\mathrm{pCR}$ following NAC was significantly lower in patients with AR-positive compared with AR-negative TNBC. Among the 7 AR-positive TNBC patients who underwent mammography in the present study, 6 presented with mammographic calcifications. In other words, of the 17 patients who presented with mammographic calcifications in the study, 6 were AR-positive. Taken together, it can be concluded that typical patients with AR-positive TNBC tend to present with calcifications on mammography and are less likely to achieve $\mathrm{pCR}$, resembling the characteristics of $\mathrm{ER} / \mathrm{PgR}$-positive tumors.

To the best of our knowledge, this is the first study to demonstrate that mammographic calcification of TNBC prior to chemotherapy may indicate the efficacy of treatment. Although further investigations are required, it can be presumed that tumors with a rich intraductal component, which often present with mammographic calcifications, are more likely to be chemotherapy-resistant. Furthermore, TNBCs present with few calcifications overall, with AR-positive tumors being more likely to present with calcifications, indicating the rich intraductal component and poor response to chemotherapy of such tumors. 

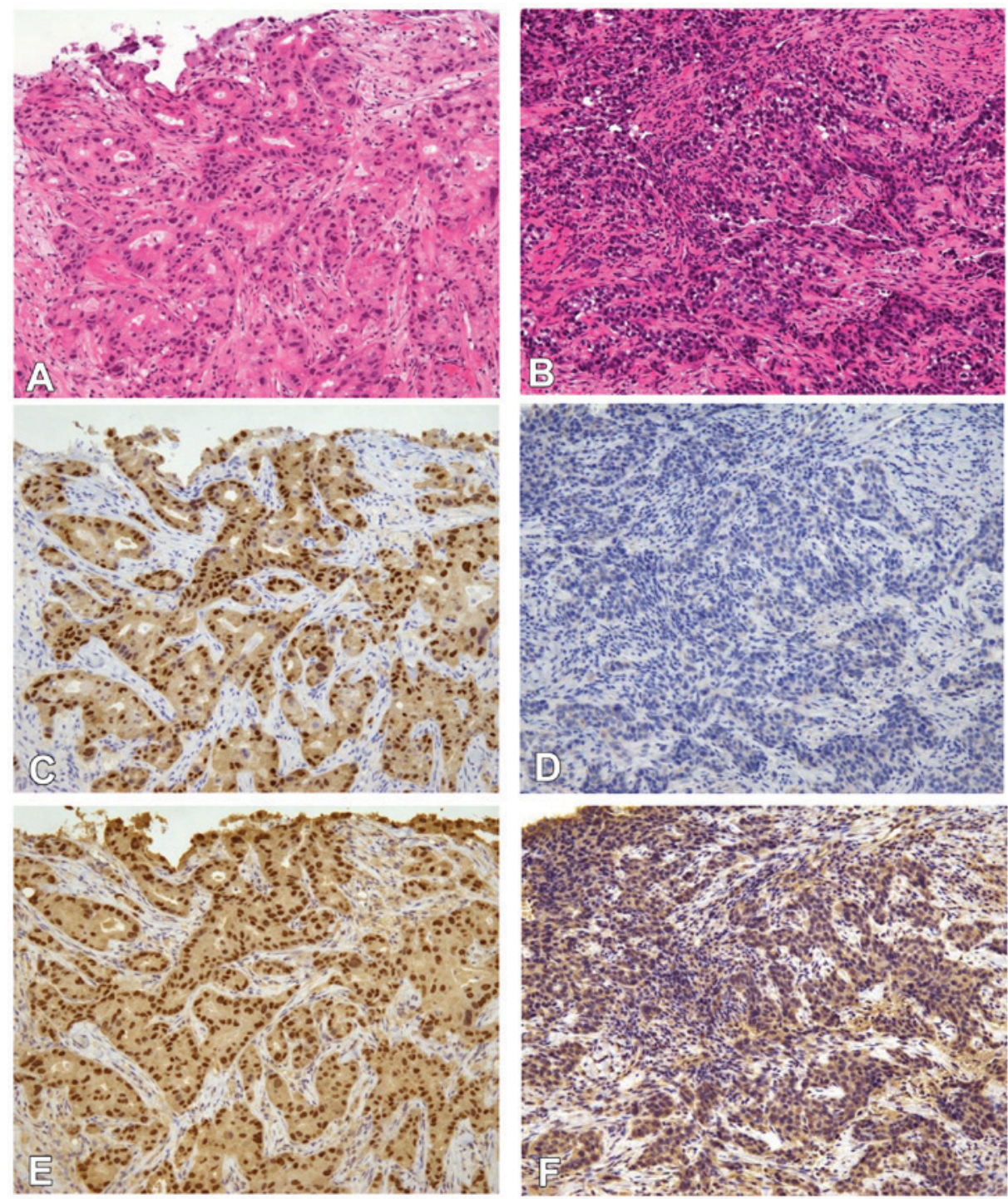

Figure 1. IHC staining of AR and FOXA1. All images are magnification, x100. (A and B) Hematoxylin and eosin staining of triple-negative IDC tissue. Representative IHC image with (C) positive and (D) negative nuclear staining for AR in triple-negative IDC tissue. Representative IHC image with (E) positive and $(\mathrm{F})$ negative FOXA1 nuclear staining in triple-negative IDC tissue. A, C and E are images from a singular specimen, and B, D and F are another set of images from a different singular specimen. IHC, immunohistochemistry; AR, androgen receptor; FOXA1, forkhead-box A1; IDC, invasive ductal carcinoma.

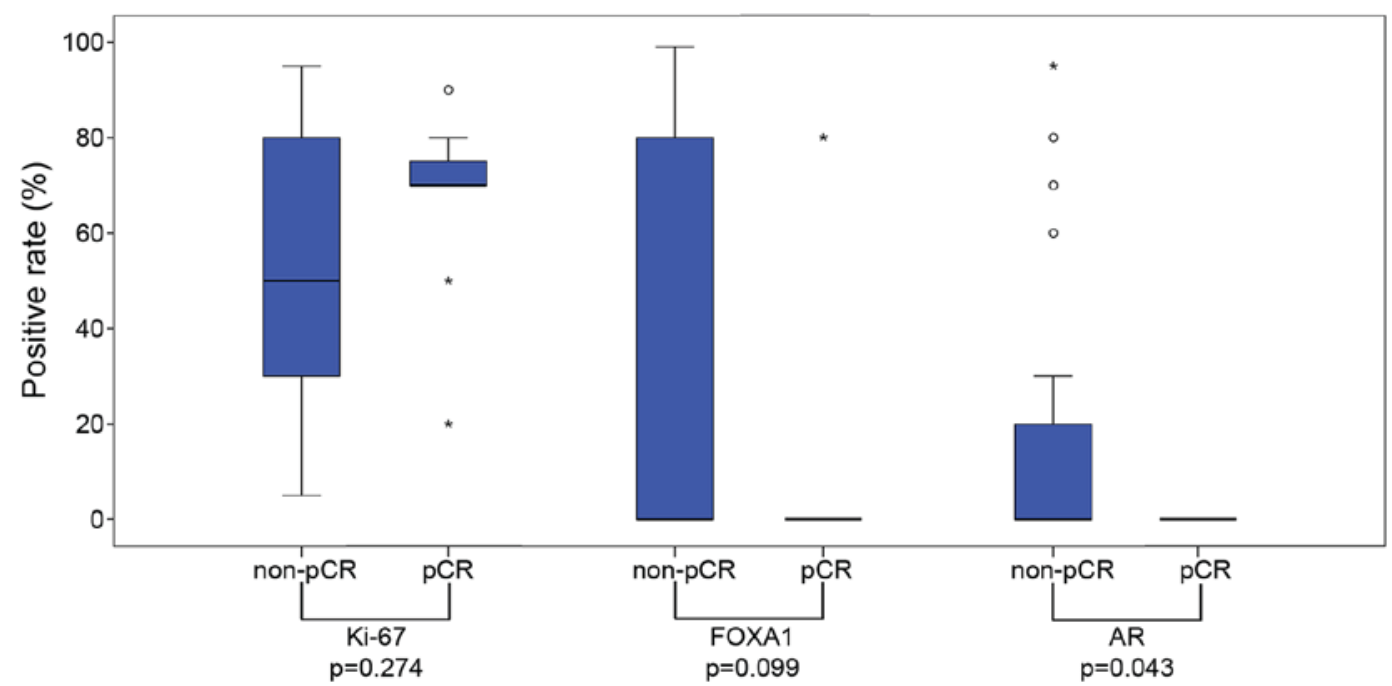

Figure 2. Box-and-whisker plot of the association between $\mathrm{pCR}$ and the immunohistochemical staining results for Ki-67, FOXA1 and AR. Circles indicate the outlier values, and asterisks indicate the extreme outlier values. The positive rate for $\mathrm{AR}$ was revealed to be significantly lower in the $\mathrm{pCR}$ group ( $\mathrm{P}=0.043$, Mann-Whitney U test). pCR, pathological complete response; FOXA1, forkhead-box A1; AR, androgen receptor. 
Although not statistically significant, certain results from the present study also indicated that chemotherapy-sensitive patients with TNBC exhibit IDC-NOS tumors rather than specific histological types of tumors. Certain researchers have assumed and recognized that special histological type tumors react poorly to chemotherapy. Hennessy et al (23) described metaplastic breast cancer as chemotherapy-resistant. The IM, M, MSL and LAR subtypes which were defined by Lehmann et al (4) were identified to correspond a specific histological type. These subtypes were reported to be a poor response for chemotherapy (4). The aforementioned data correspond with the result from the present study that the $\mathrm{pCR}$ group did not include special histological type tumors. Therefore, the present study hypothesized that special histological type tumors are more likely to be chemotherapy-resistant, whereas IDC-NOS type tumors are more likely to be sensitive to chemotherapy.

Denkert et al (24) reported that the expression of $\mathrm{Ki}-67$ is predictive for the response to NAC in the majority of breast cancer subtypes, including TNBC. Accordingly, the BL1 subtype, the most chemotherapy-sensitive subgroup in the study by Masuda et al (11), presents with high Ki-67 expression. This can be explained by the observation that highly proliferative tumors exhibit an improved response to NAC; these data are in agreement with the results of the present study showing that the pCR group presented with higher Ki-67 scores than the non-pCR group.

FOXA1 is a key determinant of ER function and endocrine response; FOXA1 functions as an important pioneer factor for the interactions between ER or AR with chromatin (25). Among the 8 AR-positive patients in the present study, all patients were FOXA1-positive, supporting a hypothesis of a correlation between AR and FOXA1 status. It is assumed that FOXA1-positive tumors share characteristics with ERor AR-positive tumors. Sasahara et al (26) reported that apocrine carcinomas were often positive for AR and FOXA1 in IHC, further indicating a correlation between AR and FOXA1.

Previous studies have suggested that tumor-infiltrating lymphocytes (TILs) are associated with pCR after NAC among patients with TNBC (27-30). Miyashita et al (27) reported that tumors with a higher histological grade and a smaller size may present with higher cluster of differentiation $8^{+}$TIL levels; this may support the result from the present study that less advanced tumors are more likely to be chemotherapy-sensitive. However, the associations between TILs and the other clinical factors investigated in the present study, including AR, calcification and histological types, remain unclear. The present study had a number of limitations. Firstly, the sample size was relatively small, potentially limiting the statistical power. In order to further confirm the conclusions, studies with larger sample sizes are required. Secondly, the patients received three types of chemotherapy regimen. Although the regimens were performed at similar rates in each of the groups, it may remain difficult to precisely compare the effectiveness.

In conclusion, the results of the present study suggest that patients with TNBC who present with clinically less advanced tumors and less frequent mammographic calcification are more likely to respond to chemotherapy. From a pathological aspect, the histological type IDC-NOS, negative
AR expression and higher Ki-67 scores were demonstrated to indicate chemotherapy sensitivity. It is necessary to be aware that TNBC comprises a heterogeneous group of cancer types and that not all TNBCs are truly chemotherapy-sensitive. The results indicate that, from standard clinical information, it may be possible to predict the effectiveness of chemotherapy and avoid the severe side effects caused by ineffective treatment. Furthermore, patients with chemotherapy-resistant TNBC should be distinguished from other patients with TNBC to enable the application of novel treatment approaches, including AR-targeted therapy.

The authors wish to declare the following conflicts of interest: Dr Akira Matsui received research funding from Chugai Pharmaceutical (Tokyo, Japan), Daiichi Sankyo (Tokyo, Japan), Eisai (Tokyo, Japan), Takeda Pharmaceutical, (Osaka, Japan), Taiho Pharmaceutical (Tokyo, Japan); also, Dr Aiko Nagayama holds stock in Chugai Pharmaceutical.

\section{Acknowledgements}

The authors thank the technicians of the Clinical Examination Department for sample preparation.

\section{References}

1. Bauer KR, Brown M, Cress RD, Parise CA and Caggiano V: Descriptive analysis of estrogen receptor (ER)-negative, progesterone receptor (PR)-negative, and HER2-negative invasive breast cancer, the so-called triple-negative phenotype: A population-based study from the California cancer registry. Cancer 109: 1721-1728, 2007.

2. Carey LA, Dees EC, Sawyer L, Gatti L, Moore DT, Collichio F, Ollila DW, Sartor CI, Graham ML and Perou CM: The triple negative paradox: Primary tumor chemosensitivity of breast cancer subtypes. Clin Cancer Res 13: 2329-2334, 2007.

3. Palma G, Frasci G, Chirico A, Esposito E, Siani C, Saturnino C, Arra C, Ciliberto G, Giordano A and D'Aiuto M: Triple negative breast cancer: Looking for the missing link between biology and treatments. Oncotarget 6: 26560-26574, 2015.

4. Lehmann BD, Bauer JA, Chen X, Sanders ME, Chakravarthy AB, Shyr Y and Pietenpol JA: Identification of human triple-negative breast cancer subtypes and preclinical models for selection of targeted therapies. J Clin Invest 121: 2750-2767, 2011.

5. Lehmann BD, Jovanović B, Chen X, Estrada MV, Johnson KN, Shyr Y, Moses HL, Sanders ME and Pietenpol JA: Refinement of triple-negative breast cancer molecular subtypes: Implications for neoadjuvant chemotherapy selection. PLoS One 11: e0157368, 2016.

6. Rouzier R, Perou CM, Symmans WF, Ibrahim N, Cristofanilli M, Anderson K, Hess KR, Stec J, Ayers M, Wagner P, et al: Breast cancer molecular subtypes respond differently to preoperative chemotherapy. Clin Cancer Res 11: 5678-5685, 2005.

7. Nwaogu I, Fayanju O, Jeffe D and Margenthaler J: Predictors of pathological complete response to neoadjuvant chemotherapy in stage II and III breast cancer: The impact of chemotherapeutic regimen. Mol Clin Oncol 3: 1117-1122, 2015.

8. Liedtke C, Mazouni C, Hess KR, André F, Tordai A, Mejia JA, Symmans WF, Gonzalez-Angulo AM, Hennessy B, Green M, et al: Response to neoadjuvant therapy and long-term survival in patients with triple-negative breast cancer. J Clin Oncol 26: 1275-1281, 2008

9. von Minckwitz G, Untch M, Blohmer JU, Costa SD, Eidtmann H, Fasching PA, Gerber B, Eiermann W, Hilfrich J, Huober J, et al: Definition and impact of pathologic complete response on prognosis after neoadjuvant chemotherapy in various intrinsic breast cancer subtypes. J Clin Oncol 30: 1796-1804, 2012.

10. Dawood S, Broglio K, Kau SW, Green MC, Giordano SH, Meric-Bernstam F, Buchholz TA, Albarracin C, Yang WT, Hennessy BT, et al: Triple receptor-negative breast cancer: The effect of race on response to primary systemic treatment and survival outcomes. J Clin Oncol 27: 220-226, 2009. 
11. MasudaH,Baggerly KA,Wang Y,Zhang Y,Gonzalez-Angulo AM, Meric-Bernstam F, Valero V, Lehmann BD, Pietenpol JA, Hortobagyi GN, et al: Differential response to neoadjuvant chemotherapy among 7 triple-negative breast cancer molecular subtypes. Clin Cancer Res 19: 5533-5540, 2013.

12. The Japanese Breast Cancer Society: General Rules for Clinical and Pathological Recording of Breast Cancer. 17th edition. Kanehara \& Co., Ltd., Tokyo, Japan, 2012.

13. Japan Radiology Society, Japanese Society of Radiologic Technology: Mammography Guideline. Japan Central Organization on Quality Assurance of Breast Cancer Screening (ed). 3rd edition. IGAKU-SHOIN Ltd., Tokyo, Japan, 2010.

14. Sobin LH, Gospodarowicz MK and Wittekind C (eds): International Union Against Cancer: TNM Classification of Malignant Tumors. 7th edition. Wiley-Blackwell, New York, 2011.

15. Donepudi MS, Kondapalli K, Amos SJ and Venkanteshan P: Breast cancer statistics and markers. J Cancer Res Ther 10: 506-511, 2014.

16. Dnistrian AM, Schwartz MK, Greenberg EJ, Smith CA and Schwartz DC: Evaluation of CA M26, CA M29, CA 15-3 and CEA as circulating tumor markers in breast cancer patients. Tumour Biol 12: 82-90, 1991 .

17. Ichihara $\mathrm{S}$ and Aoyama $\mathrm{H}$ : Intraductal carcinoma of the breast associated with high levels of circulating tumor-associated antigens (CA 15-3 and NCC-ST-439). Cancer 73: 2181-2185, 1994.

18. Wolff AC, Hammond ME, Hicks DG, Dowsett M, McShane LM Allison KH, Allred DC, Bartlett JM, Bilous M, Fitzgibbons P, et al: Recommendations for human epidermal growth factor receptor 2 testing in breast cancer: American Society of Clinical Oncology/College of American Pathologists clinical practice guideline update. J Clin Oncol 31: 3997-4013, 2013.

19. Greenwood HI, Heller SL, Kim S, Sigmund EE, Shaylor SD and Moy L: Ductal carcinoma in situ of the breasts: Review of MR imaging features. Radiographics 33: 1569-1588, 2013.

20. Li J, Chen C, Gu Y, Di G, Wu J, Liu G and Shao Z: The role of mammographic calcification in the neoadjuvant therapy of breast cancer imaging evaluation. PLoS One 9: e88853, 2014.

21. Bae MS, Park SY, Song SE, Kim WH, Lee SH, Han W, Park IA, Noh DY and Moon WK: Heterogeneity of triple-negative breast cancer: Mammographic, US and MR imaging features according to androgen receptor expression. Eur Radiol 25: 419-427, 2015.

22. Asano Y, Kashiwagi S, Onoda N, Kurata K, Morisaki T, Noda S Takashima T, Ohsawa M, Kitagawa S and Hirakawa K: Clinical verification of sensitivity to preoperative chemotherapy in cases of androgen receptor-expressing positive breast cancer. Br J Cancer 114: 14-20, 2016.
23. Hennessy BT, Gonzalez-Angulo AM, Stemke-Hale K, Gilcrease MZ, Krishnamurthy S, Lee JS, Fridlyand J, Sahin A, Agarwal R, Joy C, et al: Characterization of a naturally occurring breast cancer subset enriched in epithelial-to-mesenchymal transition and stem cell characteristics. Cancer Res 69: 4116-4124, 2009.

24. Denkert C, Loibl S, Müller BM, Eidtmann H, Schmitt WD, Eiermann W, Gerber B, Tesch H, Hilfrich J, Huober J, et al: Ki67 levels as predictive and prognostic parameters in pretherapeutic breast cancer core biopsies: A translational investigation in the neoadjuvant GeparTrio trial. Ann Oncol 24: 2786-2793, 2013.

25. Tokunaga E, Hisamatsu Y, Tanaka K, Yamashita N, Saeki H, Oki E, Kitao H and Maehara Y: Molecular mechanisms regulating the hormone sensitivity of breast cancer. Cancer Sci 105: 1377-1383, 2014

26. Sasahara M, Matsui A, Ichimura Y, Hirakata Y, Murata Y and Marui E: Overexpression of androgen receptor and forkhead-box A1 protein in apocrine breast carcinoma. Anticancer Res 34: 1261-1267, 2014.

27. Miyashita M, Sasano H, Tamaki K, Chan M, Hirakawa H, Suzuki A, Tada H, Watanabe G, Nemoto N, Nakagawa S, et al: Tumor-infiltrating CD8+ and FOXP3+ lymphocytes in triplenegative breast cancer: Its correlation with pathological complete response to neoadjuvant chemotherapy. Breast Cancer Res Treat 148: 525-534, 2014

28. Ono M,Tsuda H,Shimizu C, YamamotoS, Shibata T, YamamotoH, Hirata T, Yonemori K, Ando M, Tamura K, et al: Tumorinfiltrating lymphocytes are correlated with response to neoadjuvant chemotherapy in triple-negative breast cancer. Breast Cancer Res Treat 132: 793-805, 2012.

29. Wang K, Xu J, Zhang T and Xue D: Tumor-infiltrating lymphocytes in breast cancer predict the response to chemotherapy and survival outcome: A meta-analysis. Oncotarget 7: 44288-44298, 2016.

30. Adams S, Gray RJ, Demaria S, Goldstein L, Perez EA, Shulman LN, Martino S, Wang M, Jones VE, Saphner TJ, et al: Prognostic value of tumor-infiltrating lymphocytes in triple-negative breast cancers from two phase III randomized adjuvant breast cancer trials: ECOG 2197 and ECOG 1199. J Clin Oncol 32: 2959-2966, 2014 